\title{
REVIEW
}

\section{Preclinical drug studies in MEN1-related neuroendocrine neoplasms (MEN1-NENs)}

\author{
Simona Grozinsky-Glasberg1', Kate E Lines², Shani Avniel-Polak¹, Chas Bountra³ and Rajesh V Thakker² \\ ${ }^{1}$ Neuroendocrine Tumor Unit, ENETS Center of Excellence, Department of Endocrinology and Metabolism, Hadassah-Hebrew University Medical Center, \\ Jerusalem, Israel \\ ${ }^{2}$ Academic Endocrine Unit, Radcliffe Department of Medicine, University of Oxford, Oxford Centre for Diabetes, Endocrinology and Metabolism (OCDEM), \\ Churchill Hospital, Oxford, UK \\ ${ }^{3}$ Structural Genomics Consortium, University of Oxford, Oxford, UK
}

Correspondence should be addressed to S Grozinsky-Glasberg: simonag@hadassah.org.il

\begin{abstract}
Neuroendocrine neoplasms (NENs) occur usually as sporadic tumours; however, rarely, they may arise in the context of a hereditary syndrome, such as multiple endocrine neoplasia type 1 (MEN1), an autosomal dominant disorder characterised by the combined development of pancreatic NENs (pNENs) together with parathyroid and anterior pituitary tumours. The therapeutic decision for sporadic pNENs patients is multi-disciplinary and complex: based on the grade and stage of the tumor, various options (and their combinations) are considered, such as surgical excision (either curative or for debulking aims), biological drugs (somatostatin analogues), targeted therapies (mTOR inhibitors or tyrosine kinases (TK)/receptors inhibitors), peptide receptor radioligand therapy (PRRT), chemotherapy, and liver-directed therapies. However, treatment of MEN1-related NENs' patients is even more challenging, as these tumours are usually multifocal with co-existing foci of heterogeneous biology and malignant potential, rendering them more resistant to the conventional therapies used in their sporadic counterparts, and therefore associated with a poorer prognosis. Moreover, clinical data using standard therapeutic options in MEN1-related NENs are scarce. Recent preclinical studies have identified potentially new targeted therapeutic options for treating MEN1-associated NENs, such as epigenetic modulators, Wnt pathway-targeting $\beta$-catenin antagonists, Ras signalling modulators, Akt/mTOR signalling modulators, novel somatostatin receptors analogues, anti-angiogenic drugs, as well as MEN1 gene replacement therapy. The present review aims to summarize these novel therapeutic opportunities for NENs developing in the context of MEN1 syndrome, with an emphasis on pancreatic NENs, as they are the most frequent ones studied in MEN1-NENs models to date; moreover, due to the recent shifting nomenclature of 'pituitary adenomas' to 'pituitary neuroendocrine neoplasms', relevant data on MEN1-pituitary tumours, when appropriate, are briefly described.
\end{abstract}

\author{
Key Words \\ - preclinical studies \\ - endocrine neoplasia \\ - MEN1 \\ - neuroendocrine neoplasms
}

(c) 2020 Society for Endocrinology Published by Bioscientifica Ltd. Printed in Great Britain
Endocrine-Related Cancer (2020) 27, R345-R355 


\section{Introduction}

\section{Multiple endocrine neoplasia (MEN) syndromes}

The term multiple endocrine neoplasia (MEN) refers to hereditary neoplastic disorders involving two or more endocrine glands within a single patient. Based on specific mutations inducing the development of specific tumours within specific endocrine glands, four major subtypes of MEN are recognized and referred to as types 1-4 (MEN1 to MEN4) (Thakker 2014). The most frequent among these conditions is MEN1, discussed below. MEN2 and MEN3 are induced by mutations in the RET (rearranged in transfection) proto-oncogene; MEN2 is characterized by the co-appearance of medullary thyroid carcinoma, pheochromocytoma and parathyroid tumours, whereas MEN3 manifests with MEN2 features except for parathyroid involvement, in the presence of a marfanoid habitus and ganglioneuromas of the lips, tongue and colon (Brandi et al. 2001). MEN4 is caused by germline mutations in CDKN1B tumor suppressor gene, commonly presenting with parathyroid and pituitary neoplasias (Alrezk et al. 2017). As MEN4 is sometimes confused for MEN1, and as rarely there is an overlap between MEN2 occurring tumours and MEN1 (Naziat et al. 2013), we briefly summarize the MEN syndromesrelated neuroendocrine neoplasms (NENs) in Table 1.

\section{Multiple endocrine neoplasia type 1 (MEN1, Wermer's syndrome)}

MEN1 was firstly described in the early twentieth century; however, it was not until 1954 when Wermer described familial occurrence in which a father and four of the nine offspring were affected (Wermer 1954). Patients with MEN1 characteristically develop tumours of the parathyroid glands with primary hyperparathyroidism ( 95\%), the anterior pituitary ( 30\%), and the pancreatic islets ( 40\%); less commonly, adrenal cortical adenomas/ carcinoma, thyroid follicular adenomas, extra-pancreatic neuroendocrine neoplasms such as duodenal gastrinoma or gastric, thymic, and bronchial carcinoids may appear (Duh et al. 1987, Grama et al. 1992, Skogseid et al. 1992, Trump et al. 1996, Thakker 2000, Thakker et al. 2012).

MEN1 is an autosomal dominant disorder induced by mutations in the tumor suppressor gene MEN1,

Table 1 MEN syndromes and related neuroendocrine neoplasms.

\section{MEN syndromes-related NENs}

(chromosome location, gene, function)

MEN1 (11q13.1; MEN1; tumour

suppressor gene) (Thakker et al. 2012)

$\frac{\text { Site (estimated penetrance) }}{\text { Enteropancreatic (30-70\%) }}$

'Foregut' (2-10\%)

Pituitary (30-40\%)

PPGL (extremely rare)

MEN2 (MEN2A) (10q11.2; RET; protooncogene) (Brandi et al. 2001)

MEN3 (MEN2B) (10q11.2; RET; protooncogene) (Brandi et al. 2001, Thakker 2014)

MEN4 (12p13.1; CDKN1B; tumour suppressor gene) (Thakker 2014, Alrezk et al. 2017)

\author{
Specific NEN \\ Gastrinomas (>40\%) \\ Insulinomas (10-30\%) \\ Glucagonomas ( $3 \%)$ \\ VIPomas $(<1 \%)$ \\ NF pNENs (20-55\%) \\ Somatostatinomas (extremely rare) \\ Other (e.g., GHRH-/PTH-RP-/ACTH-secreting) \\ Thymic, bronchial, gastric NENs \\ Prolactinomas (20\%) \\ ACTH, TSH, GH+PRL, GH, NF (each 2-9\%) \\ Pheochromocytomas $(<1 \%)$ \\ MTC (90\%) \\ Pheochromocytomas (50\%) \\ ACTH-secreting (Naziat et al. 2013) \\ MTC (>90\%) \\ Pheochromocytomas (40-50\%) \\ ACTH-secreting (single case report) (Kasturi et al. 2017) \\ Duodenal and pancreatic NENs (Agarwal et al. 2009, Tonelli \\ et al. 2014) \\ Bronchial and gastric NENs (Molatore et al. 2010, Malanga \\ et al. 2012) \\ ACTH-/GH-secreting, NF (Pellegata et al. 2006, Tichomirowa \\ et al. 2012, Occhi et al. 2013, Sambugaro et al. 2015) \\ Small-cell neuroendocrine cervical carcinoma (Georgitsi 2010)
}

alnsufficient numbers reported to provide prevalence information.ACTH, adrenocortical hormone; CDKN1B, cyclin-dependent kinase inhibitor 1B (p27Kip1) gene; GHRH, growth hormone releasing hormone; MTC, medullary thyroid carcinoma; NENs, neuroendocrine neoplasms; NF, non-functioning; pNENs, pancreatic neuroendocrine neoplasms; PRL, prolactin; RET, rearranged during transfection gene; TSH, thyroid stimulating hormone; VIPomas, vasointestinal polypeptide secreting tumours.

(c) 2020 Society for Endocrinology Published by Bioscientifica Ltd. Printed in Great Britain 
which encodes a 610-amino acid protein, menin (Thakker et al. 2012, Kamilaris \& Stratakis 2019). However, in up to $10-30 \%$ of MEN1 patients no mutation in the MEN1 gene can be diagnosed, as the regular approaches fail to detect possible mutations in non-coding and regulatory regions as well as to identify phenocopies. Next-generation sequencing (NGS), a novel sequencing technology, may bypass these limitations, increasing the strength and efficacy of genetic analysis (Marini et al. 2015, de Laat et al. 2016).

Prior to $1980, \sim 80 \%$ of MEN1-related deaths were caused by gastrinoma-derived gastric acid hypersecretion inducing multiple gastro-intestinal ulcers, bleeding and perforation; improvements in pharmacological control of the hypergastrinemia and related gastric acid hypersecretion have strongly reduced mortality related to these complications. Noteworthy, most of MEN1-related pancreatic or thymic NENs patients ( $70-90 \%)$ will require therapeutic intervention during their life with the disease, including surgery and/or systemic therapy (somatostatin analogues, peptide-receptor radioligand therapy, everolimus, loco-regional therapies or chemotherapy) due to tumor progression/recurrence/multi-focality (De Laat et al. 2014, Faggiano et al. 2020, Oleinikov et al. 2020). Despite the advances in their treatment, the life expectancy of MEN1-patients remains shorter than normal population (mean age at death $\sim 55$ years) (Norton et al. 2015), with death prevalently occurring as result of the malignant progression of pancreatic and thymic NENs, which are responsible for $\sim 50 \%$ and $\sim 24 \%$ of fatalities, respectively (Marini et al. 2017).

\section{MEN1-NENs: limitations of current therapies}

The existing therapeutic options for the various NENs have not been formally evaluated in MEN1 patients, being extrapolated from non-MEN1 NENs patients (Pieterman et al. 2020). There is scarcity of evidence reporting on these anti-tumour therapies specifically in MEN1-NENs patients. The optimal treatment for these patients is challenging, as MEN1-NENs are multiple, multicentric, pose a higher metastatic potential and are relatively insensitive to treatment (Dean et al. 2000, Frost et al. 2018). The multi-focality of MEN1-NENs and their unpredictable malignant potential pose difficulties for the timing and extent of curative surgery. As a result, these patients frequently require additional nonsurgical treatments, such as biotherapies (somatostatin analogues, SSAs), molecular-targeted therapies (mTOR inhibitors or tyrosine kinase (TK)/receptors inhibitors), peptide-receptor radioligand therapy (PRRT), chemotherapy and/or loco-regional therapies. The choice of optimal anti-tumour therapies for MEN1-NENs patients is challenging and needs the involvement of experienced multi-disciplinary teams inside referral centers of excellence.

\section{Preclinical studies on emerging therapies in MEN1-NENs}

Since the discovery of the MEN1 gene in 1997, the elucidation of the molecular function of its protein product, menin, has been challenging; nonetheless, biochemical, proteomics, genetics and genomics approaches have identified many potential roles for menin, which all converge on gene expression regulation (Dreijerink et al. 2017). Briefly, menin is ubiquitously expressed and functions as a nuclear key scaffold protein in a tissue-specific manner, displaying opposing roles between different organs, either as a bona fide tumor suppressor in endocrine organs yet essential as promoter of leukemogenesis in mouse models; these effects are probably the result of menin's capacity to dichotomously regulate gene expression, as well as to functionally crosstalk with a multitude of proteins and signalling pathways involved in cell behaviour such as gene transcription, genome stability, cell division, cell cycle control and epigenetic regulation (Matkar et al. 2013). Specifically, in the nucleus, menin interacts with the transcription factor JunD and the protein arginine methyltransferase (PRMT) 5 to suppress transcription of target genes; it binds to chromatin-modifying protein complexes such as the histone modifiers mixed lineage leukemia proteins (MLL)- 1 and -2-containing complexes and Smad3 (a TGF- $\beta$ signalling component) to promote transcription of target genes; it restricts Wnt pathway target genes transcription by blocking $\beta$-catenin from entering the nucleus; in the cytoplasm, menin binds to Akt inhibiting the mechanistic target of rapamycin (mTOR pathway) downstream of PI3K and hampers ERK-dependent K-Ras phosphorylation preventing the interaction between the guanine nucleotide exchange factor son of sevenless (SOS) and K-Ras (Stalberg et al. 2004, Milne et al. 2005, Wang et al. 2011, Chamberlain et al. 2014, Frost et al. 2018) (Fig. 1).

Preclinical in vitro and in vivo models of cancer are instrumental in studying genes functions, in deciphering the biology of tumor initiation and progression, and in performing preclinical studies aimed at testing 


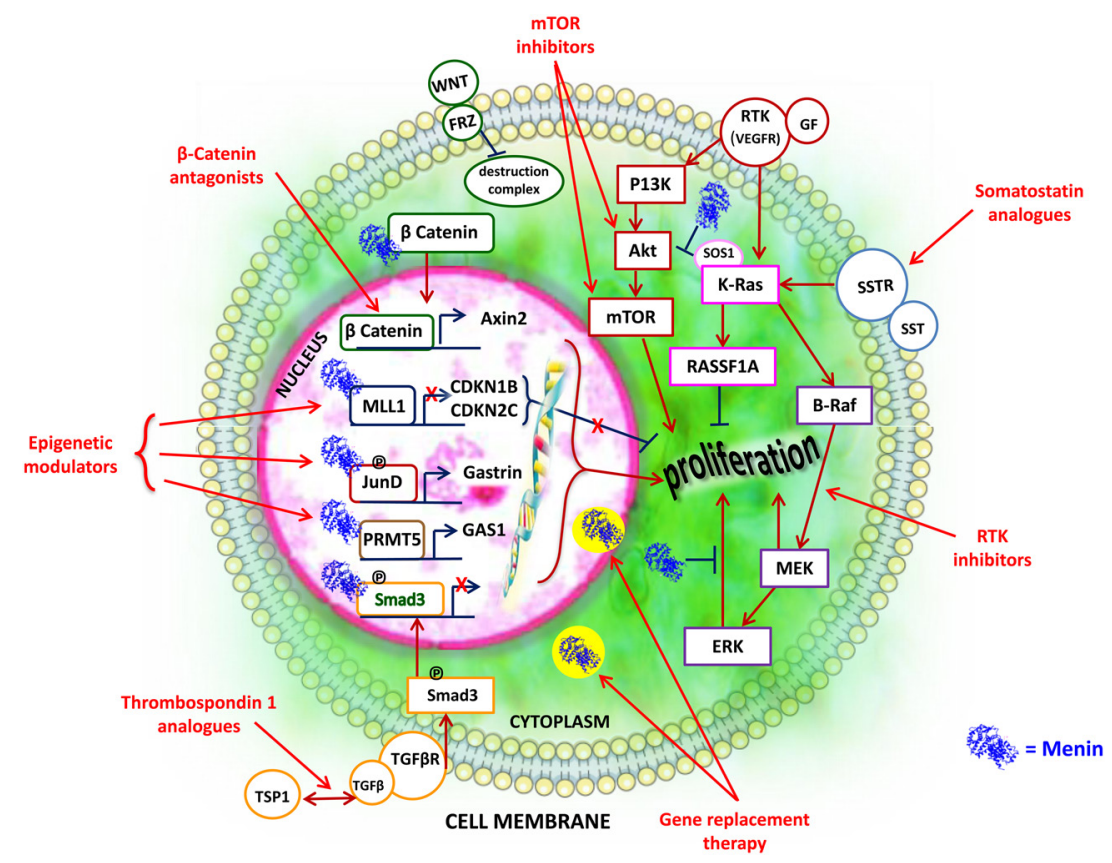

\section{Figure 1}

Menin-associated tumourigenic pathways and the possible targeting therapies to be considered. Menin, which is encoded by the MEN1 gene, has several nuclear and cytoplasmic functions. Loss of expression of the tumour suppressor protein menin (drawn as blue-azure symbol) results in increased cell proliferation by altering multiple different signalling pathways. In the nucleus, menin can alter gene transcription by: interacting with JunD or the protein arginine N-methyltransferase (PRMT) 5 to repress transcription of target genes, e.g. Gastrin and Gas1, respectively; binding to mixed linage leukaemia proteins MLL1 and/or MLL2, and the TGF- $\beta$ signalling component Smad3, to promote transcription of target genes; and regulates the Wnt pathway by preventing $\beta$-catenin from entering the nucleus and therefore preventing transcription of Wnt pathway target genes. In the cytoplasm, menin inhibits: the mTOR pathway by binding to Akt, which is downstream of PI3K in the receptor tyrosine kinase (RTK) signalling pathway, and preventing its translocation to the plasma membrane; and K-Ras induced proliferation, by possible inhibition of ERK dependent phosphorylation and prevention of the interaction between SOS and K-Ras. GF, growth factor; P13K, phosphoinositide 3-kinase; Akt, protein kinase B; mTOR, mechanistic target of rapamycin; FRZ, fizzled; MLL, mixed lineage leukemia; CDKN, cyclin dependent kinase inhibitor; GAS1, growth arrest specific 1; SMAD3, mothers against decapentaplegic hormone 3; TGF $\beta(R)$, transforming growth factor beta (receptor); TSP1, thrombospondin 1; SST(R), somatostatin (receptor); SOS1, sons of sevenless 1; RASSF1A, ras associated domain family member 1 isoform A; MEK, mitogen activated protein kinase; ERK, extra signal-related kinase. Data from Frost et al. (2018).

novel therapies. Several MEN1 animal models have been generated in different organisms by introducing loss-of-function mutations in the orthologues of the human MEN1 gene, which closely resemble the tumor spectrum and associated hormonal changes seen in human disease, although individual tumor behaviour may be variable (Wiedemann \& Pellegata 2016, Mohr \& Pellegata 2017). The increased understanding of menin function has allowed for the preclinical development of menin-targeted therapies for NENs, which are discussed below. Noteworthy, most of the research performed to date on MEN1-NENs almost exclusively involves pancreatic tumours extracted from MEN1-mice models, which will be therefore elaborated in the present review; moreover, due to the recent shifting nomenclature of 'pituitary adenomas' to 'pituitary neuroendocrine neoplasms', relevant data on MEN1pituitary tumours, when appropriate, are briefly described (Asa et al. 2017).

\section{Epigenetic modulators}

Menin has been demonstrated to play a role in gene transcription, through the regulation of epigenetic mechanisms, including histone modifications. For example, menin has been shown to interact with a number of histone-modifying proteins including histone methyltransferases (e.g. mixed linage leukaemia 1 (MLL1) and protein arginine methyltransferase 5 (PRMT5)) and acetyltransferase complexes (HDACs) to regulate the expression of tumor suppressor genes including $C D K N 1 B$ and GAS1 (Pieterman et al. 2014, Thakker 2014). The use of epigenetic-targeting compounds may therefore have utility in MEN1-associated tumours. Preclinical studies have indicated that JQ1, an inhibitor of the bromo and extra terminal domain (BET) family of proteins that bind to acetylated histone residues to promote gene transcription may have efficacy in pancreatic, bronchial and pituitary NENs as in vitro studies revealed that JQ1 decreased proliferation and increased apoptosis of 
pancreatic, pituitary and bronchial NEN cell lines, as well as reducing ACTH secretion from the ACTH-secreting pituitary cell lines, AtT20 (Lines et al. 2017, 2020). Furthermore, in vivo, assessment using a pancreatic $\beta$-cellspecific conditional Men1-knockout mouse model that develops pNENs, revealed that JQ1 decreased proliferation and increased apoptosis of pNENs (Lines et al. 2017). In addition, CPI203, another BET inhibitor, has also been reported to reduce pNEN proliferation in a BON-1 xenograft model (Wong et al. 2014).

To date, the potential utility of histone deacetylases inhibitors (HDACi) has been demonstrated in some sporadic NENs, whereas specific studies on MEN1-NENs models are limited. Namely, inhibition of HDAC5 using the compound LMK-235 has been reported as a potential therapeutic target in pNENs (Wanek et al. 2018). In addition, the class I HDAC1/3 inhibitor etinostat was able to inhibit master regulator proteins in $42 \%$ of metastatic gastro-entero-pancreatic NENs, and to reduce tumour growth in a small intestinal NEN xenograft mouse model (Alvarez et al. 2018). The HDAC inhibitor suberoylanilide hydroxamic acid (SAHA) has also been reported to decrease proliferation and increase apoptosis, this time in a GH3 rat pituitary NEN cell line (Sangeetha et al. 2009). Recently, some HDACi such as vorinostat (SAHA), romidepsin or panobinostat were approved by FDA for specific hematologic malignancies (Suraweera et al. 2018); however, limited efficacy has been shown in patients with sporadic pNENs (Jin et al. 2016). Although epigenetic modulators seem attractive as potential therapies for NENs patients, further clinical studies using selective compounds alone or in combination with other anticancer agents are needed to understand their real therapeutic potential, and specifically for MEN1-NENs patients.

In addition, it is well established that menin forms a complex with MLL and Ash2 proteins to promote histone 3, lysine 4 (H3K4) methylation, which in turn increases the expression of anti-proliferative genes including cyclin-dependent kinase (CDK) inhibitors that encode p27 and p18 (Hughes et al. 2004, Karnik et al. 2005, Milne et al. 2005). Furthermore, preclinical studies have demonstrated that genetic ablation of the retinoblastoma binding protein 2 ( $\mathrm{Rbp} 2$ ), which acts as a H3K4 demethylase, can reduce proliferation of pNEN cells, and reduce pancreatic tumour burden in a Men1 conditional knockout mice (Lin et al. 2011, Maggi et al. 2016). Moreover, Rbp2 expression has been reported to be elevated in NENs (Maggi et al. 2016). Therefore, modulators of CDK expression, including inhibitors of
Rbp2 could provide a novel therapeutic approach for MEN1-associated NENs.

\section{Wnt pathway-targeting $\beta$-catenin antagonists}

Menin can reduce cell proliferation through Wnt $/ \beta$-catenin signalling by promoting $\beta$-catenin phosphorylation and its transfer from the nucleus. The absence of menin leads to nuclear $\beta$-catenin accumulation and transcriptional activation of the target genes (Matkar et al. 2013). As previously mentioned, menin possesses dichotomous functions by positively or negatively regulating different gene expression and by interacting with a multitude of proteins with diverse functions. It was suggested that menin may either promote or inhibit Wnt signalling in certain stages of islet tumor development as well as in certain cell types: for example, menin was shown to be essential for canonical Wnt/ $\beta$-catenin signalling in cultured rodent islet tumor cells yet it was suggested that it may also inhibit Wnt signalling to prevent $\beta$ cells from early-stage tumorigenesis; however, in Men1-null mouse embryonic fibroblasts (MEF) menin promoted nuclear export of $\beta$-catenin, suppressing its transcriptional activity. Nevertheless, the menin/Wnt/ $\beta$-catenin interactions remain yet to be explored.

Data on Wnt signalling modulators in MEN1-related tumor models is limited. In a study using both Men1null mouse embryonic fibroblasts (MEF) and insulinoma tissues from $\beta$-cell-specific Men1-knockout mice (with a nuclear accumulation of $\beta$-catenin), Cao et al. have shown that overexpression of menin reduces $\beta$-catenin nuclear accumulation and its transcriptional activity, and that menin directly interacts with $\beta$-catenin carrying it out of the nucleus via nuclear-cytoplasmic shuttling (Cao et al. 2009).

In another study using MEN1-deficient mice developing pNENs (RIP-Cre, with pancreatic $\beta$-cell conditional knockout of menin), the additional conditional knockout of $\beta$-catenin decreased the number and the size of pancreatic tumours and increased mice survival (Jiang et al. 2014). Moreover, the use of a $\beta$-catenin antagonist (PKF115-584) decreased pNEN cell proliferation, suggesting that Wnt-signalling modulators may provide a novel approach for the treatment of MEN1NENs patients.

\section{Ras/Raf/MEK/ERK pathway modulators}

Aberrant activation of the RAS-RAF-MEK-ERK (MAPK) pathway is implicated in numerous cancers. Initial studies have been shown that NENs display 
activating mutations in the rat sarcoma (Ras) family of signal-transducing genes, over-activity of p21(Ras)signalling pathways, or constitutive activation of upstream or downstream effectors of Ras including growth factor receptors or PI(3)-kinase and Raf/mitogenactivated protein kinases; Ras depends on protein kinase C delta (PKCd)-mediated survival pathways (Xia et al. 2007). In a study by Kim et al., menin overexpression in a pro-oncogenic RAS-transformed murine NIH3T3 cells decreased cell proliferation and tumor growth in athymic mice, restraining RAS oncogenic effects (Kim et al. 1999).

K-Ras, a member of the Ras family, paradoxically suppressed growth in pancreatic endocrine cells in a mice model, and this effect depended on the antiproliferative Ras effector RASSF1A and blockade of the Raf/MAPK pathway by menin; stimulation of ERK1/2 phosphorylation combined with a menin inhibitor synergistically enhanced proliferation, whereas inhibition of MAPK signalling created a lethal effect in the setting of menin loss. These insights suggest potential strategies for targeting menin-sensitive endocrine tumors (Chamberlain et al. 2014). Recently, using an ATII-specific

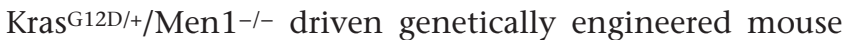
model, it was shown that deficiency of menin results in the accumulation of DNA damage and antagonizes oncogenic Kras-induced senescence during tumorigenesis (Qiu et al. 2020).

Following promising pre-clinical data, the novel selective ERK1/2 inhibitor BVD-523 (ulixertinib) entered clinical trials with encouraging antitumor activity in patients with solid tumours harbouring mutations in the MAPK/ERK pathway; however, data on NENs and specifically on MEN-NENs, is still limited (Germann et al. 2017, Sullivan et al. 2018).

\section{Akt/mTOR signalling modulators}

Mammalian (mechanistic) target of rapamycin (mTOR), a serine/threonine protein kinase involved in the regulation of different cellular functions (cell proliferation, migration, activation of transcription factors, etc.), is constitutively activated in NENs as a catalytic subunit of 2 distinct complexes: the rapamycin-sensitive mTORC1 which activates the downstream proteinkinase S6k and eIF4B, inducing cell proliferation; and the rapamycin-insensitive mTORC2, which compensatory phosphorylates Akt promoting its overactivation and the development of resistance to mTORC1 inhibitors (mTORi) such as rapamycin, respectively (Grozinsky-Glasberg \& Pavel 2012).
Although the mTORC1 inhibitor RAD001 (everolimus) is already in clinical use for non-MEN1-NENs of different origins, data on menin and Akt/mTOR pathway signalling is limited. Razmara et al. aimed to assess the impact of menin expression (alone, or in addition to co-treatment with rapamycin) on cell proliferation in a cell-line model including menin-silenced BON-1 cells (Razmara et al. 2018). Lack of menin enhanced mTORC2-Akt activation as well as the rapamycin-induced pAkt and a direct negative regulation between menin and the rapamycin-mediated mTORC2-Akt activation was observed. Apparently, menin is essential in mTORC1/C2 crosstalk and may influence the response to mTORi in pNENs patients.

Another study by Wang et al. also suggested that menin is an important negative regulator of Akt kinase activity, this time using a Men $1^{+/-}$mice model bearing islet adenomas (Wang et al. 2011). IHC staining for pAkt(S473) and menin of 18 months Men1+/- mice derived islet adenomas vs WT demonstrated that expression of pAkt(S473) in islet adenomas correlates with loss of menin expression, meaning that menin downregulates AKT activity and inhibits both Akt induced proliferation and Akt anti-apoptosis effects.

Recently, Wong et al. demonstrated that the coexistence of other mutations (e.g. Pten loss) together with Men1 loss accelerate the neuroendocrine tumorigenesis in two genetically engineered mouse models of well differentiated pNENs (Wong et al. 2020). Their data highlight the importance of the PI3K/AKT/ mTOR pathway in NENs genesis in mice and that treatment with the mTOR inhibitor rapamycin delayed the growth of pNENs as well as the growth of pituitary NENs, resulting in prolonged survival in these mice.

\section{Anti-angiogenic drugs}

Angiogenesis, or the formation of new capillary blood vessels, is a fundamental process in cancer development, including in NENs. The proangiogenic signalling molecule vascular endothelial growth factor (VEGF) and its cognate receptor VEGF receptor 2 (VEGFR-2) play a central role in angiogenesis (Zhao \& Adjei 2015). Initial antiangiogenic drugs inhibited VEGF/VEGFR signalling inducing a transient response, followed usually by tumor progression as other pathways compensate for the initial inhibition, such as increase in tumour hypoxia, in the expression of pro-angiogenic factors including VEGFA or fibroblast growth factors (FGFs family, ephrin A1, and c-Met activation, etc.); therefore, a simultaneous co-targeting of VEGF, PDGF, FGF, etc. and their receptors may improve clinical outcomes. 
Chu et al. evaluated the possible structural, molecular and functional microvascular aberrations contributing to development and maintenance of pNENs using a Men1 mouse model (Chu et al. 2013). They have showed that the increased vascular density of pNENs in Men1 mice was paralleled by an early and extensive redistribution of pericytes, alterations supported by variations in expression of several angiogenic regulators and potentiated by hypoxia. They also demonstrated that both vascular reactivity/constriction and blood perfusion of tumor arterioles are significantly altered in response to glucose and L-nitro-arginine methyl ester (L-NAME, a nitric oxide synthase inhibitor), suggesting a possible role as therapy.

Few studies evaluated the effect of different antiangiogenic molecules on tumor growth, invasiveness and metastatic potential using the Rip1Tag2 transgenic mouse model of non-MEN1-pNENs: nindetanib, targeting VEGF, PDGF, FGF receptors and c-Src, induced a strong antiangiogenic response with decrease in tumor growth and no increase in invasiveness or metastatic spread (Bill et al. 2015); sunitinib, a VEGF-inhibitor, reduced initially the tumor burden followed by an increase in tumor invasiveness and metastasis, which were reversed eventually by a dual inhibition of c-Met and VEGF signalling with several compounds including crizotinib or cabozantinib (Sennino et al. 2012); finally, functionally active peptides derived from endogenous angiogenesis inhibitors (such as tumstatin, endostatin and the second type 1 repeat of thrombospondin-1), suppressed angiogenesis and reduced tumour growth, whereas their genetic-induced deficiency accelerated tumor growth and decreased mice survival (Xie et al. 2011). Although these studies were performed in Rip1Tag2 transgenic mouse model, the effects of angiogenesis modulation on tumor control seem promising and further research using MEN1NENs models is warranted.

\section{Somatostatin analogues (SSAs)}

Somatostatin (SST) and its analogues were demonstrated to have anti-proliferative effects in a variety of tumour cells by inhibiting the mitogenic signalling of growth factor receptor kinases, by inducing apoptosis, or by inhibiting the secretion of insulin-like growth factor-I, etc., and are considered today the mainstay of therapy in sporadic NENs (Grozinsky-Glasberg et al. 2008). However, data on their effects in MEN1-NENs models is limited.

Quinn et al. tested the effect of pasireotide (SOM230, a pan-SST receptor (SSTR) agonist that acts via SSTR1,2,3 and 5), on insulin secretion, glucose levels, tumor growth, and mice survival using an MEN1 transgenic mouse model (Quinn et al. 2012). SOM230 demonstrated significant antisecretory, antiproliferative and proapoptotic activity in the MEN1 model of insulinoma. Moreover, the effects of pasireotide were also evaluated in a Men1+/- mouse model developing pancreatic and pituitary NENs (Walls et al. 2016). Pasireotide decreased proliferation and increased apoptosis of pNENs, suppressed tumour growth and tumor number, increased mice survival and resulted in prevention of tumor development. These results suggest the potential utility of SSAs such as pasireotide as chemo-preventive or prophylactic treatment of pancreatic and pituitary NENs in patients with MEN1, as supported by some recent clinical data (Cioppi et al. 2017, Faggiano et al. 2020). Further prospective studies of the effects of SOM230 in MEN1-NENs patients are warranted. Noteworthy, most of NENs express both SSTR and dopamine receptor 2 (D2DR), and evaluating the potential of SSTR2-D2DR co-targeting in these tumors seem attractive; however, further investigation is required to assess the possible role of chimeric agonists in NENs in general, and particularly in MEN1-NENs (Zitzmann et al. 2013, Herrera-Martínez et al. 2019).

\section{MEN1 gene replacement ('living drug') studies}

The concept of MEN1 gene replacement therapy is based on the evidence that majority of MEN1-NENs have loss of heterozygosity (LOH) for the MEN1 allele located on chr 11q13, consistent with a tumor suppressor role for menin, and that mutations in menin are associated with tumor development. To date, few studies were performed to investigate whether inducing menin overexpression by viral/ non-viral gene delivery methods could reverse the phenotype in human tumor cells low in menin expression and to suppress tumor cell proliferation.

Walls et al. demonstrated initially that Men $1^{+/-}$miceoriginating tumours (pNENs and pituitary NENs) had higher proliferation rates compared with their respective normal tissues (Walls et al. 2012a). Using a knockout Men1+/- mouse model which developed pituitary NENs, the transauricular injection of a recombinant adenoviral serotype 5 vector (rAd5) (containing Men1 cDNA, rAd5MEN1) directly in the pituitary tumours of female mice increased menin expression and decreased tumor proliferation (Walls et al. 2012b). Finally, in a pNENbearing Men1 gene KO transgenic mice (insulin-secreting) model, the injection of Oct-AAVP-TNF (a hybrid adenoassociated virus and phage (AAVP) vector displaying 
active octreotide) decreased tumor metabolism, insulin secretion and tumor size, and improved mice survival (Smith et al. 2016). Gene therapy for MEN1-NENs may represent a promising cutting-edge therapy. However, there are major issues to be solved including optimal delivery, risks of several off-target/adverse effects including immune response and mutagenesis and efficacy (Goswami et al. 2019). Further pre-clinical research is warranted before defining the possible role of MEN1 gene replacement therapy in patients with MEN1-NENs.

\section{Conclusions and future directions}

Recent studies have further attempted to decipher the complex molecular alterations and pathways involved in the development and progression of MEN1-NENs, including insights in the genes involved in chromatin remodelling and epigenetic regulation, in mTOR-, K-RAS- or b-catenin/Wnt signalling, as well as on SSTR signalling. In addition, preclinical studies have suggested the possible efficacy of epigenetic modulators, Wnt pathway targeting $\beta$-catenin antagonists, multi-SSTRtargeted analogues and MEN1 gene replacement therapy in treating MEN1-related NENs. However, further and throughout evaluation of such emerging treatments in clinical trials is warranted to assess their outcomes and limitations, and before their possible use in patients with MEN1-related NENs. Further research on the tissuespecific actions of menin may reveal potential therapeutic targets and facilitate translational studies in MEN1-NENs. New directions may include the development of specific and advanced MEN1-NENs preclinical models (e.g., novel cellular models, xenograft models, or three-dimensional tumor cell organoid models), evaluating the delay in tumorigenesis after the loss of both copies of the Men1 gene, as well as further elucidation of the relation between menin loss and the various molecular pathways involved in the tissue-selective anti-tumor function of menin.

\section{Declaration of interest}

S G G has received research support from Novartis and Ipsen and honoraria from Novartis, Ipsen, Pfizer, and Lexicon. K E L and R V T have received research support from Bristol Myers Squibb. The other authors have nothing to disclose.

\section{Funding}

R V T is a Wellcome Trust and NIHR senior investigator and receives funding from the NIHR Oxford Biomedical Research Centre Programme; KE L is an Oxford-BMS research fellow.

(c) 2020 Society for Endocrinology Published by Bioscientifica Ltd. Printed in Great Britain

\section{References}

Agarwal SK, Mateo CM \& Marx SJ 2009 Rare germline mutations in cyclin-dependent kinase inhibitor genes in multiple endocrine neoplasia type 1 and related states. Journal of Clinical Endocrinology and Metabolism 94 1826-1834. (https://doi.org/10.1210/jc.20082083)

Alrezk R, Hannah-Shmouni F \& Stratakis CA 2017 MEN4 and CDKN1B mutations: the latest of the MEN syndromes. Endocrine-Related Cancer 24 T195-T208. (https://doi.org/10.1530/ERC-17-0243)

Alvarez MJ, Subramaniam PS, Tang LH, Grunn A, Aburi M, Rieckhof G, Komissarova EV, Hagan EA, Bodei L, Clemons PA, et al. 2018 A precision oncology approach to the pharmacological targeting of mechanistic dependencies in neuroendocrine tumors. Nature Genetics 50 979-989. (https://doi.org/10.1038/s41588-018-0138-4)

Asa SL, Casar-Borota O, Chanson P, Delgrange E, Earls P, Ezzat S, Grossman A, Ikeda H, Inoshita N, Karavitaki N, et al. 2017 From pituitary adenoma to pituitary neuroendocrine tumor (PitNET): an International Pituitary Pathology Club proposal. Endocrine-Related Cancer 24 C5-C8. (https://doi.org/10.1530/ERC-17-0004)

Bill R, Fagiani E, Zumsteg A, Antoniadis H, Johansson D, Haefliger S, Albrecht I, Hilberg F \& Christofori G 2015 Nintedanib is a highly effective therapeutic for neuroendocrine carcinoma of the pancreas (PNET) in the Rip1Tag2 transgenic mouse model. Clinical Cancer Research 21 4856-4867. (https://doi.org/10.1158/1078-0432.CCR-143036)

Brandi ML, Gagel RF, Angeli A, Bilezikian JP, Beck-Peccoz P, Bordi C, Conte-Devolx B, Falchetti A, Gheri RG, Libroia A, et al. 2001 Guidelines for diagnosis and therapy of MEN type 1 and type 2 . Journal of Clinical Endocrinology and Metabolism 86 5658-5671. (https://doi.org/10.1210/jcem.86.12.8070)

Cao Y, Liu R, Jiang X, Lu J, Jiang J, Zhang C, Li X \& Ning G 2009 Nuclear-cytoplasmic shuttling of menin regulates nuclear translocation of \{beta\}-catenin. Molecular and Cellular Biology 29 5477-5487. (https://doi.org/10.1128/MCB.00335-09)

Chamberlain CE, Scheel DW, McGlynn K, Kim H, Miyatsuka T, Wang J, Nguyen V, Zhao S, Mavropoulos A, Abraham AG, et al. 2014 Menin determines K-RAS proliferative outputs in endocrine cells. Journal of Clinical Investigation 124 4093-4101. (https://doi.org/10.1172/ JCI69004)

Chu X, Gao X, Jansson L, Quach M, Skogseid B \& Barbu A 2013 Multiple microvascular alterations in pancreatic islets and neuroendocrine tumors of a Men1 mouse model. American Journal of Pathology 182 2355-2367. (https://doi.org/10.1016/j. ajpath.2013.02.023)

Cioppi F, Cianferotti L, Masi L, Giusti F \& Brandi ML 2017 The LAROMEN1 study: a longitudinal clinical experience with octreotide longacting release in patients with multiple endocrine neoplasia type 1 syndrome. Clinical Cases in Mineral and Bone Metabolism 14 123-130. (https://doi.org/10.11138/ccmbm/2017.14.1.123)

De Laat JM, Pieterman CR, Van Den Broek MF, Twisk JW, Hermus AR, Dekkers OM, De Herder WW, Van Der Horst-Schrivers AN, Drent ML, Bisschop PH, et al. 2014 Natural course and survival of neuroendocrine tumors of thymus and lung in MEN1 patients. Journal of Clinical Endocrinology and Metabolism 99 3325-3333. (https://doi.org/10.1210/jc.2014-1560)

De Laat JM, van der Luijt RB, Pieterman CRC, Oostveen MP, Hermus AR, Dekkers OM, de Herder WW, van der HorstSchrivers AN, Drent ML, Bisschop PH, et al. 2016 MEN1 redefined, a clinical comparison of mutation-positive and mutation-negative patients. BMC Medicine 14 182. (https://doi.org/10.1186/s12916-0160708-1)

Dean PG, Van Heerden JA, Farley DR, Thompson GB, Grant CS, Harmsen WS \& Ilstrup DM 2000 Are patients with multiple endocrine neoplasia type I prone to premature death? World Journal of Surgery 24 1437-1441. (https://doi.org/10.1007/s002680010237) 
Dreijerink KMA, Timmers HTM \& Brown M 2017 Twenty years of menin: emerging opportunities for restoration of transcriptional regulation in MEN1. Endocrine-Related Cancer 24 T135-T145. (https:// doi.org/10.1530/ERC-17-0281)

Duh QY, Hybarger CP, Geist R, Gamsu G, Goodman PC, Gooding GA \& Clark OH 1987 Carcinoids associated with multiple endocrine neoplasia syndromes. American Journal of Surgery 154 142-148. (https://doi.org/10.1016/0002-9610(87)90305-9)

Faggiano A, Modica R, Lo Calzo F, Camera L, Napolitano V, Altieri B, de Cicco F, Bottiglieri F, Sesti F, Badalamenti G, et al. 2020 Lanreotide therapy vs active surveillance in MEN1-related pancreatic neuroendocrine tumors $<2$ centimeters. Journal of Clinical Endocrinology and Metabolism 105 78-84. (https://doi.org/10.1210/ clinem/dgz007)

Frost M, Lines KE \& Thakker RV 2018 Current and emerging therapies for PNETS in patients with or without MEN1. Nature Reviews: Endocrinology 14 216-227. (https://doi.org/10.1038/nrendo.2018.3)

Georgitsi M 2010 MEN-4 and other multiple endocrine neoplasias due to cyclin-dependent kinase inhibitors (p27Kip1 and p18INK4C) mutations. Best Practice and Research: Clinical Endocrinology and Metabolism 24 425-437. (https://doi.org/10.1016/j.beem.2010.01.001)

Germann UA, Furey BF, Markland W, Hoover RR, Aronov AM, Roix JJ, Hale M, Boucher DM, Sorrell DA, Martinez-Botella G, et al. 2017 Targeting the MAPK signaling pathway in cancer: promising preclinical activity with the novel selective ERK1/2 inhibitor BVD523 (ulixertinib). Molecular Cancer Therapeutics 16 2351-2363. (https://doi.org/10.1158/1535-7163.MCT-17-0456)

Goswami R, Subramanian G, Silayeva L, Newkirk I, Doctor D, Chawla K, Chattopadhyay S, Chandra D, Chilukuri N \& Betapudi V 2019 Gene therapy leaves a vicious cycle. Frontiers in Oncology 9 297. (https:// doi.org/10.3389/fonc.2019.00297)

Grama D, Skogseid B, Wilander E, Eriksson B, Martensson H, Cedermark B, Ahren B, Kristofferson A, Oberg K \& Rastad J 1992 Pancreatic tumors in multiple endocrine neoplasia type 1: clinical presentation and surgical treatment. World Journal of Surgery 16 611-618; discussion 618. (https://doi.org/10.1007/BF02067335)

Grozinsky-Glasberg S \& Pavel M 2012 Inhibition of mTOR in carcinoid tumors. Targeted Oncology 7 189-195. (https://doi.org/10.1007/ s11523-012-0225-x)

Grozinsky-Glasberg S, Shimon I, Korbonits M \& Grossman AB 2008 Somatostatin analogues in the control of neuroendocrine tumours: efficacy and mechanisms. Endocrine-Related Cancer 15 701-720. (https://doi.org/10.1677/ERC-07-0288)

Herrera-Martínez AD, van den Dungen R, Dogan-Oruc F, Van Koetsveld PM, Culler MD, De Herder WW, Luque RM, Feelders RA \& Hofland LJ 2019 Effects of novel somatostatin-dopamine chimeric drugs in 2D and 3D cell culture models of neuroendocrine tumors. Endocrine-Related Cancer 26 585-599. (https://doi.org/10.1530/ERC19-0086)

Hughes CM, Rozenblatt-Rosen O, Milne TA, Copeland TD, Levine SS, Lee JC, Hayes DN, Shanmugam KS, Bhattacharjee A, Biondi CA, et al. 2004 Menin associates with a trithorax family histone methyltransferase complex and with the Hoxc8 locus. Molecular Cell 13 587-597. (https://doi.org/10.1016/S1097-2765(04)00081-4)

Jiang X, Cao Y, Li F, Su Y, Li Y, Peng Y, Cheng Y, Zhang C, Wang W \& Ning G 2014 Targeting beta-catenin signaling for therapeutic intervention in MEN1-deficient pancreatic neuroendocrine tumours. Nature Communications 5 5809. (https://doi.org/10.1038/ ncomms6809)

Jin N, Lubner SJ, Mulkerin DL, Rajguru S, Carmichael L, Chen H, Holen KD \& LoConte NK 2016 A Phase II trial of a histone deacetylase inhibitor panobinostat in patients with low-grade neuroendocrine tumors. Oncologist 21 785-786. (https://doi. org/10.1634/theoncologist.2016-0060)

Kamilaris CDC \& Stratakis CA 2019 Multiple endocrine neoplasia Type 1 (MEN1): an update and the significance of early genetic and clinical diagnosis. Frontiers in Endocrinology 10 339. (https://doi.org/10.3389/ fendo.2019.00339)

Karnik SK, Hughes CM, Gu X, Rozenblatt-Rosen O, McLean GW, Xiong Y, Meyerson M \& Kim SK 2005 Menin regulates pancreatic islet growth by promoting histone methylation and expression of genes encoding p27Kip1 and p18INK4c. PNAS 102 14659-14664. (https://doi.org/10.1073/pnas.0503484102)

Kasturi K, Fernandes L, Quezado M, Eid M, Marcus L, Chittiboina P, Rappaport M, Stratakis CA, Widemann B \& Lodish M 2017 Cushing disease in a patient with multiple endocrine neoplasia type $2 \mathrm{~B}$. Journal of Clinical and Translational Endocrinology Case Reports 4 1-4. (https://doi.org/10.1016/j.jecr.2017.02.001)

Kim YS, Burns AL, Goldsmith PK, Heppner C, Park SY, Chandrasekharappa SC, Collins FS, Spiegel AM \& Marx SJ 1999 Stable overexpression of MEN1 suppresses tumorigenicity of RAS. Oncogene 18 5936-5942. (https://doi.org/10.1038/sj.onc.1203005)

Lin W, Cao J, Liu J, Beshiri ML, Fujiwara Y, Francis J, Cherniack AD, Geisen C, Blair LP, Zou MR, et al. 2011 Loss of the retinoblastoma binding protein 2 (RBP2) histone demethylase suppresses tumorigenesis in mice lacking Rb1 or Men1. PNAS 108 13379-13386. (https://doi.org/10.1073/pnas.1110104108)

Lines KE, Filippakopoulos P, Stevenson M, Müller S, Lockstone HE, Wright B, Knapp S, Buck D, Bountra C \& Thakker RV 2020 Effects of epigenetic pathway inhibitors on corticotroph tumour att20 cells. Endocrine-Related Cancer 27 163-174. (https://doi.org/10.1530/ERC19-0448)

Lines KE, Stevenson M, Filippakopoulos P, Müller S, Lockstone HE, Wright B, Grozinsky-Glasberg S, Grossman AB, Knapp S, Buck D, et al. 2017 Epigenetic pathway inhibitors represent potential drugs for treating pancreatic and bronchial neuroendocrine tumors. Oncogenesis 6 e332. (https://doi.org/10.1038/oncsis.2017.30)

Maggi EC, Trillo-Tinoco J, Struckhoff AP, Vijayaraghavan J, Del Valle L \& Crabtree JS 2016 Retinoblastoma-binding protein 2 (RBP2) is frequently expressed in neuroendocrine tumors and promotes the neoplastic phenotype. Oncogenesis 5 e257. (https://doi.org/10.1038/ oncsis.2016.58)

Malanga D, De Gisi S, Riccardi M, Scrima M, De Marco C, Robledo M \& Viglietto G 2012 Functional characterization of a rare germline mutation in the gene encoding the cyclin-dependent kinase inhibitor p27Kip1 (CDKN1B) in a Spanish patient with multiple endocrine neoplasia-like phenotype. European Journal of Endocrinology 166 551-560. (https://doi.org/10.1530/EJE-11-0929)

Marini F, Giusti F \& Brandi ML 2015 Genetic test in multiple endocrine neoplasia type 1 syndrome: an evolving story. World Journal of Experimental Medicine 5 124-129. (https://doi.org/10.5493/wjem. v5.i2.124)

Marini F, Giusti F, Tonelli F \& Brandi ML 2017 Management impact: effects on quality of life and prognosis in MEN1. Endocrine-Related Cancer 24 T227-T242. (https://doi.org/10.1530/ERC-17-0203)

Matkar S, Thiel A \& Hua X 2013 Menin: a scaffold protein that controls gene expression and cell signaling. Trends in Biochemical Sciences $\mathbf{3 8}$ 394-402. (https://doi.org/10.1016/j.tibs.2013.05.005)

Milne TA, Hughes CM, Lloyd R, Yang Z, Rozenblatt-Rosen O, Dou Y, Schnepp RW, Krankel C, LiVolsi VA, Gibbs D, et al. 2005 Menin and MLL cooperatively regulate expression of cyclin-dependent kinase inhibitors. PNAS 102 749-754. (https://doi.org/10.1073/ pnas.0408836102)

Mohr H \& Pellegata NS 2017 Animal models of MEN1. Endocrine-Related Cancer 24 T161-T177. (https://doi.org/10.1530/ERC-17-0249)

Molatore S, Marinoni I, Lee M, Pulz E, Ambrosio MR, degli Uberti EC, Zatelli MC \& Pellegata NS 2010 A novel germline CDKN1B mutation causing multiple endocrine tumors: clinical, genetic and functional characterization. Human Mutation 31 E1825-E1835. (https://doi. org/10.1002/humu.21354)

Naziat A, Karavitaki N, Thakker R, Ansorge O, Sadler G, Gleeson F, Cranston T, McCormack A, Grossman AB \& Shine B 2013 Confusing https://erc.bioscientifica.com

https://doi.org/10.1530/ERC-20-0127 (c) 2020 Society for Endocrinology Published by Bioscientifica Ltd. Printed in Great Britain 
genes: a patient with MEN2A and Cushing's disease. Clinical Endocrinology 78 966-968. (https://doi.org/10.1111/cen.12072)

Norton JA, Krampitz G \& Jensen RT 2015 Multiple endocrine neoplasia: genetics and clinical management. Surgical Oncology Clinics of North America 24 795-832. (https://doi.org/10.1016/j.soc.2015.06.008)

Occhi G, Regazzo D, Trivellin G, Boaretto F, Ciato D, Bobisse S, Ferasin S, Cetani F, Pardi E, Korbonits M, et al. 2013 A novel mutation in the upstream open reading frame of the CDKN1B gene causes a MEN4 phenotype. PLoS Genetics 9 e1003350. (https://doi. org/10.1371/journal.pgen.1003350)

Oleinikov K, Uri I, Jacob H, Epshtein J, Benson A, Ben-Haim S, Atlan K, Tal I, Meirovitz A, Maimon O, et al. 2020 Long-term outcomes in MEN-1 patients with pancreatic neuroendocrine neoplasms: an Israeli specialist center experience. Endocrine 68 222-229. (https:// doi.org/10.1007/s12020-020-02217-4)

Pellegata NS, Quintanilla-Martinez L, Siggelkow H, Samson E, Bink K, Höfler H, Fend F, Graw J \& Atkinson MJ 2006 Germ-line mutations in p27Kip1 cause a multiple endocrine neoplasia syndrome in rats and humans. PNAS 103 15558-15563. (https://doi.org/10.1073/ pnas.0603877103)

Pieterman CRC, Conemans EB, Dreijerink KMA, de Laat JM, Timmers HT, Vriens MR \& Valk GD 2014 Thoracic and duodenopancreatic neuroendocrine tumors in multiple endocrine neoplasia type 1: natural history and function of menin in tumorigenesis. Endocrine-Related Cancer 21 R121-R142. (https://doi. org/10.1530/ERC-13-0482)

Pieterman CRC, Sadowski SM, Maxwell JE, Katz MHG, Lines KE, Heaphy CM, Tirosh A, Blau JE, Perrier N, Lewis MA, et al. 2020 HEREDITARY ENDOCRINE TUMOURS: CURRENT STATE-OF-THEART AND RESEARCH OPPORTUNITIES: MEN1-related pancreatic NETs: identification of unmet clinical needs and future directives. Endocrine-Related Cancer 27 T9-T25. (https://doi.org/10.1530/ERC-190441)

Qiu H, Jin BM, Wang ZF, Xu B, Zheng QF, Zhang L, Zhu LY, Shi S, Yuan JB, Lin X, et al. 2020 MEN1 deficiency leads to neuroendocrine differentiation of lung cancer and disrupts the DNA damage response. Nature Communications 11 1009. (https://doi.org/10.1038/ s41467-020-14614-4)

Quinn TJ, Yuan Z, Adem A, Geha R, Vrikshajanani C, Koba W, Fine E, Hughes DT, Schmid HA \& Libutti SK 2012 Pasireotide (SOM230) is effective for the treatment of pancreatic neuroendocrine tumors (PNETs) in a multiple endocrine neoplasia type 1 (MEN1) conditional knockout mouse model. Surgery 152 1068-1077. (https:// doi.org/10.1016/j.surg.2012.08.021)

Razmara M, Monazzam A \& Skogseid B 2018 Reduced menin expression impairs rapamycin effects as evidenced by an increase in mTORC2 signaling and cell migration. Cell Communication and Signaling 16 64. (https://doi.org/10.1186/s12964-018-0278-2)

Sambugaro S, Di Ruvo M, Ambrosio MR, Pellegata NS, Bellio M, Guerra A, Buratto M, Foschini MP, Tagliati F, degli Uberti E, et al. 2015 Early onset acromegaly associated with a novel deletion in CDKN1B 5'UTR region. Endocrine 49 58-64. (https://doi.org/10.1007/ s12020-015-0540-y)

Sangeetha SR, Singh N, Vender JR \& Dhandapani KM 2009 Suberoylanilide hydroxamic acid (SAHA) induces growth arrest and apoptosis in pituitary adenoma cells. Endocrine 35 389-396. (https:// doi.org/10.1007/s12020-009-9159-1)

Sennino B, Ishiguro-Oonuma T, Wei Y, Naylor RM, Williamson CW, Bhagwandin V, Tabruyn SP, You WK, Chapman HA, Christensen JG, et al. 2012 Suppression of tumor invasion and metastasis by concurrent inhibition of c-Met and VEGF signaling in pancreatic neuroendocrine tumors. Cancer Discovery 2 270-287. (https://doi. org/10.1158/2159-8290.CD-11-0240)

Skogseid B, Larsson C, Lindgren PG, Kvanta E, Rastad J, Theodorsson E, Wide L, Wilander E \& Oberg K 1992 Clinical and genetic features of adrenocortical lesions in multiple endocrine neoplasia type 1. Journal of Clinical Endocrinology and Metabolism 75 76-81. (https://doi. org/10.1210/jcem.75.1.1352309)

Smith TL, Yuan Z, Cardo-Vila M, Sanchez Claros C, Adem A, Cui MH, Branch CA, Gelovani JG, Libutti SK, Sidman RL, et al. 2016 AAVP displaying octreotide for ligand-directed therapeutic transgene delivery in neuroendocrine tumors of the pancreas. PNAS 113 2466-2471. (https://doi.org/10.1073/pnas.1525709113)

Stalberg P, Grimfjard P, Santesson M, Zhou Y, Lindberg D, Gobl A, Oberg K, Westin G, Rastad J, Wang S, et al. 2004 Transfection of the multiple endocrine neoplasia type 1 gene to a human endocrine pancreatic tumor cell line inhibits cell growth and affects expression of JunD, delta-like protein 1 /preadipocyte factor-1, proliferating cell nuclear antigen, and QM/Jif-1. Journal of Clinical Endocrinology and Metabolism 89 2326-2337. (https://doi.org/10.1210/jc.2003-031228)

Sullivan RJ, Infante JR, Janku F, Lee Wong DJL, Sosman JA, Keedy V, Patel MR, Shapiro GI, Mier JW, Tolcher AW, et al. 2018 First-in-class ERK1/2 inhibitor ulixertinib (BVD-523) in patients with MAPK mutant advanced solid tumors: results of a phase I dose-escalation and expansion study. Cancer Discovery 8 184-195. (https://doi. org/10.1158/2159-8290.CD-17-1119)

Suraweera A, O'Byrne KJ \& Richard DJ 2018 Combination therapy with histone deacetylase inhibitors (HDACi) for the treatment of cancer: achieving the full therapeutic potential of HDACi. Frontiers in Oncology 8 92. (https://doi.org/10.3389/fonc.2018.00092)

Thakker RV 2000 Multiple endocrine neoplasia type 1. Endocrinology and Metabolism Clinics of North America 29 541-567. (https://doi. org/10.1016/S0889-8529(05)70150-X)

Thakker RV 2014 Multiple endocrine neoplasia type 1 (MEN1) and type 4 (MEN4). Molecular and Cellular Endocrinology 386 2-15. (https://doi. org/10.1016/j.mce.2013.08.002)

Thakker RV, Newey PJ, Walls GV, Bilezikian J, Dralle H, Ebeling PR, Melmed S, Sakurai A, Tonelli F, Brandi ML, et al. 2012 Clinical practice guidelines for multiple endocrine neoplasia type 1 (MEN1). Journal of Clinical Endocrinology and Metabolism $972990-3011$. (https://doi.org/10.1210/jc.2012-1230)

Tichomirowa MA, Lee M, Barlier A, Daly AF, Marinoni I, Jaffrain-Rea ML, Naves LA, Rodien P, Rohmer V, Faucz FR, et al. 2012 Cyclindependent kinase inhibitor 1B (CDKN1B) gene variants in AIP mutation-negative familial isolated pituitary adenoma kindreds. Endocrine-Related Cancer 19 233-241. (https://doi.org/10.1530/ERC11-0362)

Tonelli F, Giudici F, Giusti F, Marini F, Cianferotti L, Nesi G \& Brandi ML 2014 A heterozygous frameshift mutation in exon 1 of cdkn1B gene in a patient affected by MEN4 syndrome. European Journal of Endocrinology 171 K7-K17. (https://doi.org/10.1530/EJE-14-0080)

Trump D, Farren B, Wooding C, Pang JT, Besser GM, Buchanan KD, Edwards CR, Heath DA, Jackson CE, Jansen S, et al. 1996 Clinical studies of multiple endocrine neoplasia type 1 (MEN1). QJM 89 653-669. (https://doi.org/10.1093/qjmed/89.9.653)

Walls GV, Reed AA, Jeyabalan J, Javid M, Hill NR, Harding B \& Thakker RV 2012a Proliferation rates of multiple endocrine neoplasia type 1 (MEN1)-associated tumors. Endocrinology 153 5167-5179. (https://doi.org/10.1210/en.2012-1675)

Walls GV, Lemos MC, Javid M, Bazan-Peregrino M, Jeyabalan J, Reed AA, Harding B, Tyler DJ, Stuckey DJ, Piret S, et al. 2012b MEN1 gene replacement therapy reduces proliferation rates in a mouse model of pituitary adenomas. Cancer Research 72 5060-5068. (https://doi. org/10.1158/0008-5472.CAN-12-1821)

Walls GV, Stevenson M, Soukup BS, Lines KE, Grossman AB, Schmid HA \& Thakker RV 2016 Pasireotide therapy of multiple endocrine neoplasia type 1-associated neuroendocrine tumors in female mice deleted for an Men1 allele improves survival and reduces tumor progression. Endocrinology 157 1789-1798. (https://doi.org/10.1210/ en.2015-1965)

Wanek J, Gaisberger M, Beyreis M, Mayr C, Helm K, Primavesi F, Jäger T, Di Fazio P, Jakab M, Wagner A, et al. 2018 Pharmacological https://erc.bioscientifica.com

https://doi.org/10.1530/ERC-20-0127 (c) 2020 Society for Endocrinology Published by Bioscientifica Ltd. Printed in Great Britain 
inhibition of class IIA HDACs by LMK-235 in pancreatic neuroendocrine tumor cells. International Journal of Molecular Science 19 3128. (https://doi.org/10.3390/ijms19103128)

Wang Y, Ozawa A, Zaman S, Prasad NB, Chandrasekharappa SC, Agarwal SK \& Marx SJ 2011 The tumor suppressor protein menin inhibits AKT activation by regulating its cellular localization. Cancer Research 71 371-382. (https://doi.org/10.1158/0008-5472.CAN-103221)

Wermer P 1954 Genetic aspects of adenomatosis of endocrine glands American Journal of Medicine 16 363-371. (https://doi. org/10.1016/0002-9343(54)90353-8)

Wiedemann T \& Pellegata NS 2016 Animal models of multiple endocrine neoplasia. Molecular and Cellular Endocrinology 421 49-59. (https://doi.org/10.1016/j.mce.2015.07.004)

Wong C, Laddha SV, Tang L, Vosburgh E, Levine AJ, Normant E, Sandy P, Harris CR, Chan CS \& Xu EY 2014 The bromodomain and extra-terminal inhibitor CPI203 enhances the antiproliferative effects of rapamycin on human neuroendocrine tumors. Cell Death and Disease 5 e1450. (https://doi.org/10.1038/cddis.2014.396)

Wong C, Tang LH, Davidson C, Vosburgh E, Chen W, Foran DJ, Notterman DA, Levine AJ \& Xu EY 2020 Two well-differentiated pancreatic neuroendocrine tumor mouse models. Cell Death and Differentiation 27 269-283. (https://doi.org/10.1038/s41418-0190355-0)

Xia S, Forman LW \& Faller DV 2007 Protein kinase C delta is required for survival of cells expressing activated p21RAS. Journal of Biological Chemistry 282 13199-13210. (https://doi.org/10.1074/jbc. M610225200)

Xie L, Duncan MB, Pahler J, Sugimoto H, Martino M, Lively J, Mundel T, Soubasakos M, Rubin K, Takeda T, et al. 2011

Counterbalancing angiogenic regulatory factors control the rate of cancer progression and survival in a stage-specific manner. PNAS 108 9939-9944. (https://doi.org/10.1073/pnas.1105041108)

Zhao Y \& Adjei AA 2015 Targeting angiogenesis in cancer therapy: moving Beyond vascular endothelial growth factor. Oncologist 20 660-673. (https://doi.org/10.1634/theoncologist.2014-0465)

Zitzmann K, Andersen S, Vlotides G, Spöttl G, Zhang S, Datta R, Culler M, Göke B \& Auernhammer CJ 2013 The novel somatostatin receptor 2/dopamine type 2 receptor chimeric compound BIM23A758 decreases the viability of human GOT1 midgut carcinoid cells. Neuroendocrinology 98 128-136. (https://doi. org/10.1159/000353784)

Received in final form 15 June 2020

Accepted 25 June 2020

Accepted Manuscript published online 25 June 2020 (c) 2020 Society for Endocrinology Published by Bioscientifica Ltd. Printed in Great Britain 